\title{
Tecnologia de lodo granular aeróbio no tratamento de esgoto doméstico: oportunidades e desafios
}

\author{
Aerobic granular sludge technology in domestic \\ wastewater treatment: opportunities and challenges
}

\section{Silvio Luiz de Souza Rollemberg' ${ }^{\oplus}$, Lorayne Queiroz de Oliveira' ${ }^{\circledR}$, Paulo Igor Milen Firmino' ${ }^{\oplus}$, André Bezerra dos Santos ${ }^{1 *} \odot$}

\begin{abstract}
RESUMO
Considerado por muitos profissionais como um dos maiores avanços do século 21 na área de tratamento de esgotos, os reatores de lodo granular aeróbio (LGA) vêm recebendo bastante atenção em termos de pesquisa e instalação em escala plena em diferentes continentes e condições climáticas. São frequentes os relatos na literatura de eficiências de remoção acima de 90\% em termos de demanda química de oxigênio, nitrogênio total e fósforo total, além da manutenção no reator de elevadas concentrações de sólidos (> $8 \mathrm{~g}$ SSV/L) sem a necessidade de decantador secundário e recirculação de lodo. Contudo, há também diversos relatos de problemas de instabilidade da biomassa, longo período de formação dos grânulos (principalmente quando se utiliza esgoto real), formação de grânulos pequenos, acúmulo de nitrito e outras questões. Esta revisão explora os mecanismos necessários para granulação em estações de tratamento de esgoto em escala plena no tratamento de esgoto sanitário, incluindo os principais grupos microbianos presentes no LGA, parâmetros-chave para a formação dos grânulos, configurações de reator etc. Além disso, discutem-se algumas questões sobre a operação e a manutenção desses sistemas em escala plena.
\end{abstract}

Palavras-chave: lodo granular aeróbio; tratamento de esgoto; tecnologias emergentes.

\begin{abstract}
Considered by many professionals as one of the greatest advances in wastewater treatment in the $21^{\text {st }}$ century, the aerobic granular sludge (AGS) reactors have received great attention in terms of research and fullscale installation in different continents and weather conditions. There are frequent reports in the literature on removal efficiencies above $90 \%$ in terms of COD, total nitrogen and total phosphorus, as well as the maintenance of high solids concentrations (> $8 \mathrm{~g}$ VSS/L) in the reactor without the need for secondary clarifier and sludge recirculation. However, there are also several reports on problems of biomass instability, long periods of granule formation (mainly when using real sewage), formation of small granules, nitrite accumulation (incomplete denitrification), and other issues. This review explores the mechanisms required for granulation in full-scale WWTP treating sanitary wastewater, including the main microbial groups present in the AGS, key granule formation parameters, reactor configurations, etc. In addition, some issues on the operation and maintenance of these fullscale systems are discussed.
\end{abstract}

Keywords: aerobic granular sludge; wastewater treatment; emerging technologies.

\section{INTRODUÇÃO}

A tecnologia de lodo ativado é atualmente o tratamento biológico de águas residuárias mais utilizado no mundo (VAN HAANDEL; VAN DER LUBBE, 2012). No entanto, ela requer diversas operações unitárias de tratamento quando se visa à remoção de nutrientes, o que resulta em maiores custos de instalação e operação, demanda de área, além de maiores gastos energéticos. Diante desse cenário, algumas tecnologias emergentes de tratamento de esgotos vêm surgindo, como a de lodo granular aeróbio (LGA), a qual foi apontada como uma das mais promissoras da atualidade (NANCHARAIAH; REDDY, 2018).
Os reatores com grânulos aeróbios têm usualmente alta eficiência de remoção de matéria orgânica e nutrientes, elevada concentração de biomassa no reator e capacidade de suportar altas cargas orgânicas (MORGENROTH et al., 1997), não requerendo uso de material suporte. Nesse sentido, além da utilização em novas estações de tratamento de esgoto (ETE), alguns autores propõem o seu uso como alternativa a sistemas de lodo ativado nos quais haja a presença de lodo floculento com más características de sedimentabilidade (VAN HAANDEL; VAN DER LUBBE, 2012).

$\mathrm{O}$ gradiente de penetração de $\mathrm{O}_{2}$ no interior dos grânulos aeróbios ocasiona a existência de zonas aeróbias, anóxicas e anaeróbias,

口

'Universidade Federal do Ceará - Fortaleza (CE), Brasil.

*Autor correspondente: andre23@ufc.br

Recebido: 24/07/2019 - Aceito: 28/11/2019 - Reg. Abes: 20190302 
possibilitando a remoção simultânea de matéria orgânica e nutrientes (DE KREUK; VAN LOOSDRECHT, 2006; LIU et al., 2010). Os grânulos apresentam forma esférica, cujo diâmetro pode variar de 0,2 a $6 \mathrm{~mm}$. A tecnologia de LGA é caracterizada por (DEZOTTI; SANT'ANNA JR.; BASSIN, 2011):

- excelente sedimentabilidade da biomassa formada, facilitando a separação sólido-líquido;

- elevada retenção/concentração de biomassa no reator, permitindo o tratamento de altas cargas orgânicas;

- formação de diferentes zonas no grânulo, possibilitando a presença de diferentes grupos microbianos e, por consequência, a ocorrência de vários processos biológicos (remoção de matéria orgânica, nitrificação, desnitrificação e remoção de fósforo);

- capacidade de suportar elevadas velocidades ascensionais de alimentação;

- menor vulnerabilidade a processos de toxicidade;

- não necessidade de material de suporte;

- redução dos custos de operação da ETE em pelo menos $20 \%$ e diminuição da demanda de área em 75\% em comparação ao sistema de lodo ativado, não requerendo decantadores secundários.

Nos últimos anos, obtiveram-se consideráveis avanços no âmbito do tratamento de esgoto doméstico com a tecnologia de LGA. Na literatura, De Kreuk e Van Loosdrecht (2006) e Liu et al. (2010) foram os pioneiros a estudar o processo de formação dos grânulos em reatores em bateladas sequenciais (RBS, reatores em que todas as fases ocorrem em um mesmo tanque) alimentados com esgoto doméstico. Paralelamente, Wang et al. (2009) avaliaram a aplicação de LGA cultivado em laboratório com esgoto sintético, e, após maturação, a biomassa foi utilizada como inóculo para o tratamento de esgoto sanitário. Ressalta-se, no entanto, que essa prática se torna inviável em escala real em razão do grande volume dos tanques (LIU et al., 2010).

No Brasil, um dos trabalhos pioneiros no âmbito do tratamento de esgoto sanitário com a tecnologia de LGA foi demonstrado por Wagner et al. (2015), em que se empregou um reator piloto para tratar esgoto de baixa carga, porém esse sistema apresentou problemas de estabilidade, ocorrendo, também, a desintegração parcial dos grânulos. Recentemente, Roberti (2018) divulgou o primeiro trabalho científico de um reator de LGA em escala plena operado no Brasil, avaliando a partida do sistema, a formação da biomassa e o desempenho do reator.

Embora haja dezenas de ETE operando com a tecnologia de LGA, há diversos relatos de problemas de instabilidade da biomassa, de longo período de formação dos grânulos quando se utiliza esgoto real (sobretudo de baixa carga orgânica), de elevada automação do sistema e, também, de falta de domínio dos processos operacionais dos reatores de LGA (LEE et al., 2010). Zhang, Hu e Lee (2016) afirmam que a estabilidade em longo prazo dos grânulos aeróbios ainda é uma questão desafiadora, além de ser considerada como a principal restrição à aplicação prática dessa tecnologia.

Diante desse cenário, esta revisão traz o estado da arte da tecnologia de LGA no tocante ao tratamento de esgoto sanitário, apresentando os mecanismos de granulação, desempenho e operação dos reatores de LGA e as questões-chave para a implantação do LGA em ETE em escala plena.

\section{BIOMASSA GRANULAR AERÓBIA}

A biomassa é considerada granular quando o diâmetro dos grânulos é superior a $0,2 \mathrm{~mm}$, e o processo de granulação em um reator é dito completo quando mais de $80 \%$ dos sólidos suspensos voláteis atendem a esse requisito (DE KREUK; HEIJNEN; VAN LOOSDRECHT, 2005). Os grânulos aeróbios possuem uma estrutura bem definida e podem ser facilmente visualizados sem necessidade de instrumentos ópticos (LIU et al., 2009).

Em razão da variedade de população microbiana, alguns autores defendem que o grânulo é formado por um miniecossistema. Dessa forma, é possível manipular o meio por intermédio das condições operacionais para favorecer espécies desejadas, selecionando os organismos pretendidos. Os principais microrganismos presentes no LGA envolvidos na remoção de matéria orgânica e nutrientes podem ser divididos nos seguintes grupos microbianos:

- Organismos heterotróficos ordinários (ordinary heterotrophic organisms - OHO): responsáveis pela oxidação da matéria orgânica na via aeróbia. A taxa máxima de crescimento $\left(\mu_{\text {máx }}\right)$ para o referido grupo encontra-se na faixa de 4 a 13,2 $\mathrm{d}^{-1}$, com coeficiente de produção celular (Y) na ordem de 0,45 g SSV/g DQO removida;

- Organismos desnitrificantes heterotróficos ordinários (denitrifying ordinary heterotrophic organisms - DOHO): responsáveis pela oxidação da matéria orgânica na via anóxica (utilizam nitrito e/ou nitrato como aceptores de elétrons). A velocidade máxima de crescimento desse grupo aproxima-se da dos OHO. São reportados valores de $\mu_{\text {máx }}$ entre 2,2 e $6 \mathrm{~d}^{-1}$, e o Y médio relatado é de $0,30 \mathrm{~g} \mathrm{SSV} / \mathrm{g} \mathrm{DQO}_{\text {removida }}$;

- Bactérias nitrificantes: são divididas em dois principais grupos, as bactérias oxidadoras de amônia (ammonia-oxidizing bacteria - AOB) e as bactérias oxidadoras de nitrito (nitrite-oxidizing bacteria - NOB). As bactérias nitrificantes possuem Y de 0,07 a $0,28 \mathrm{~g} \mathrm{SSV} / \mathrm{g} \mathrm{N}_{\text {oxidado }}$ e caracterizam-se por baixa taxa de crescimento, com valores médios de $\mu_{\text {máx }}$ de 0,77 e $1,08 \mathrm{~d}^{-1}$ para AOB e NOB, respectivamente. Existem ainda as bactérias anaeróbias oxidadoras de amônia (anaerobic ammonia oxidation - ANAMMOX), as quais oxidam o nitrogênio na forma do íon amônio $\left(\mathrm{NH}_{4}^{+}\right)$diretamente a nitrogênio gasoso $\left(\mathrm{N}_{2}\right)$, sendo o nitrito $\left(\mathrm{NO}_{2}{ }^{-}\right)$o aceptor de elétrons. As ANAMMOX possuem a menor taxa de crescimento entre 
as bactérias que podem estar presentes no grânulo, com valores de $\mu_{\text {máx }}$ próximos a 0,065 e 0,4 $\mathrm{d}^{-1}$ (ISAKA et al., 2006);

- Organismos acumuladores de fósforo (polyphosphate-accumulating organisms - PAO): em condições anaeróbias, capturam substratos orgânicos (ácidos graxos voláteis - AGV) e armazenam-nos como poli-hidroxialcanoatos (PHA). Na fase aeróbia subsequente, os $\mathrm{PAO}$ podem absorver quantidades excessivas de ortofosfatos para recuperar os níveis intracelulares de fósforo e oxidar o PHA armazenado. Quando o aceptor de elétrons é o nitrito ou o nitrato (em substituição ao oxigênio), a assimilação/absorção de fósforo pode ocorrer pelos organismos desnitrificantes acumuladores de fósforo (denitrifying polyphosphate-accumulating organisms - DPAO). Em sistemas aeróbios convencionais, o lodo contém 2,5\% de P, no entanto lodo enriquecido com organismos acumuladores de fósforo pode apresentar até $40 \%$ de P. Alguns estudos mostraram taxas de crescimento máximas próximas a $1-3 \mathrm{~d}^{-1}$ (SANTOS, 2014);

- Organismos acumuladores de glicogênio (glycogen-accumulating organisms - GAO): têm o potencial de competir diretamente com os PAO para a absorção dos mesmos substratos em condições anaeróbias, mas não são capazes de promover a liberação ou a absorção subsequente de fósforo. Quando o aceptor de elétrons é o nitrito ou o nitrato (em substituição ao oxigênio), o acúmulo de glicogênio ocorre pelos organismos do tipo desnitrificantes acumuladores de glicogênio (denitrifying glycogen-accumulating organisms - DGAO). Alguns estudos mostraram que os GAO possuem taxa de crescimento máxima ligeiramente superior à dos PAO, com valores próximos a 2-5 $\mathrm{d}^{-1}$ (SANTOS, 2014).

A formação de LGA ocorre em etapas, e podem-se utilizar diversos tipos de inóculos, entre eles o anaeróbio (NANCHARAIAH; REDDY, 2018; ROLLEMBERG et al., 2018). Entretanto, geralmente têm sido usados flocos de lodo ativado para a partida do sistema, visando à rápida formação dos grânulos (LIU; LIU, 2006; NANCHARAIAH; REDDY, 2018). Nesse sentido, citam-se também algumas experiências brasileiras na granulação natural com esgoto sanitário (XAVIER et al., 2018).

Conforme apresentado por Rollemberg et al. (2018), o processo de formação de grânulos aeróbios é afetado por diversos fatores, tais como: configuração do reator, tensão de cisalhamento, carga orgânica aplicada, tempo de sedimentação, entre outros. Entre esses fatores, é importante destacar a tensão de cisalhamento, a qual está relacionada com a aeração do sistema, sendo de vital importância na formação e manutenção dos grânulos, pois provoca o aumento da produção de substâncias poliméricas extracelulares (SPE) nos grânulos, auxiliando assim na aglomeração inicial da biomassa para formar o LGA. Além disso, a tensão de cisalhamento atua no controle de filamentos na superfície dos grânulos (ZHOU et al., 2014). Todavia, altas taxas de cisalhamento implicam altas taxas de aeração, o que pode ocasionar elevado consumo energético, sendo inviável em plantas de tratamento em escala real.

Para a formação de grânulos compactos e regulares sem o consumo excessivo de energia, Rollemberg et al. (2018) recomendam velocidades superficiais de ar entre 1 e 1,5 cm/s. Além dessa estratégia, também se propôs, na literatura, a aeração intermitente como maneira de reduzir o consumo energético, porém essa prática não apresentou resultados satisfatórios em termos de estabilidade nem de desempenho (PRONK et al., 2015).

Outro fator-chave para a granulação é o tempo de sedimentação, considerado uma pressão de seleção essencial para a remoção de lodo filamentoso do reator. O tempo de sedimentação também pode ser utilizado, no reator, como parâmetro de controle que visa à seleção de biomassa com velocidade mínima de sedimentação (QIN; LIU, 2008). Em reatores de LGA em escala plena geralmente têm sido observados valores abaixo de 30 minutos (QIN; LIU, 2008; ROLLEMBERG et al., 2019).

Com relação ao tamanho ótimo dos grânulos, alguns trabalhos sugeriram tamanhos específicos objetivando o melhor rendimento na remoção de carbono e de nutrientes. Zhang et al. (2011) indicaram que o tamanho de grânulo menor do que $1 \mathrm{~mm}$ proporcionava melhor sedimentabilidade e estabilidade de operação em longo prazo, resultado similar ao sugerido por Toh et al. (2003). Entretanto, referindo-se a reatores em escala real tratando efluentes com altas cargas orgânicas volumétricas $(\mathrm{COV})$, manter um grânulo tão pequeno exigiria forças de cisalhamento muito altas, com elevado consumo de energia. Consequentemente, recomendou-se a faixa de 1 a $3 \mathrm{~mm}$ de tamanho dos grânulos como a ideal para a operação de RBS em escala plena (TOH et al., 2003).

O tamanho dos grânulos também foi descrito como fator de seleção dos seus grupos funcionais. Liu et al. (2015) notaram relação entre essa dimensão e a comunidade microbiana: os grânulos entre 0,6 e 1,2 mm favoreciam $\mathrm{AOB}$, e os entre 1,2 e 1,8 mm favoreciam NOB.

\section{REATORES UTILIZADOS PARA CULTIVO DOS GRÂNULOS}

Os grânulos aeróbios são geralmente cultivados em RBS. Dessa forma, todas as etapas de reação e de decantação acontecem no mesmo tanque. Embora o desenvolvimento de LGA aconteça preferencialmente em RBS, também é possível a sua formação em sistemas contínuos (HOU et al., 2017). Os reatores utilizados para cultivo dos grânulos podem ser divididos de acordo com a Figura 1.

\section{Reatores em batelada}

Os RBS utilizados no cultivo de LGA são geralmente operados em ciclos operacionais com as seguintes fases sequenciais:

- enchimento;

- reação; 
- $\quad$ sedimentação dos sólidos em suspensão;

- descarga do efluente;

- repouso.

No entanto esse sistema de RBS convencional apresenta algumas desvantagens operacionais, como:

- para realizar o descarte do efluente, é necessária uma válvula de descarte automatizada;

- após o descarte, rapidamente se deve fazer a nova alimentação, com curto espaço de tempo entre ambas as operações. Uma falha no descarte ocasiona perda de biomassa e até inundação da ETE, caso não seja previsto um sistema de extravasamento;

- nos sistemas com RBS convencional, a alimentação geralmente dura poucos minutos, o que necessita de bombas de elevada potência por conta da vazão (DEZOTTI; SANT’ANNA JR.; BASSIN, 2011; BRK AMBIENTAL, 2018).

Diante dos problemas apresentados, propôs-se uma modificação dos RBS convencionais, a qual é denominada de RBS de volume constante (PRONK et al., 2015). Nesse sistema, as etapas de alimentação e de descarte ocorrem simultaneamente, ou seja, à medida que o afluente entra no reator (parte inferior), o efluente tratado é removido (parte superior). Portanto, o sistema é composto das seguintes fases:

- enchimento/descarte;

- reação;

- $\quad$ sedimentação.

É importante dizer que a tecnologia $\mathrm{Nereda}^{\circledR}$ normalmente é operada como RBS de volume constante (ROLLEMBERG et al., 2019).

Os reatores em batelada podem ou não ser precedidos de tanques de equalização, a depender da concepção do projeto. Em algumas plantas, tem sido observada a existência de dois ou mais RBS (sistemas modulares). Nesse caso, enquanto um reator está em fase de enchimento, os

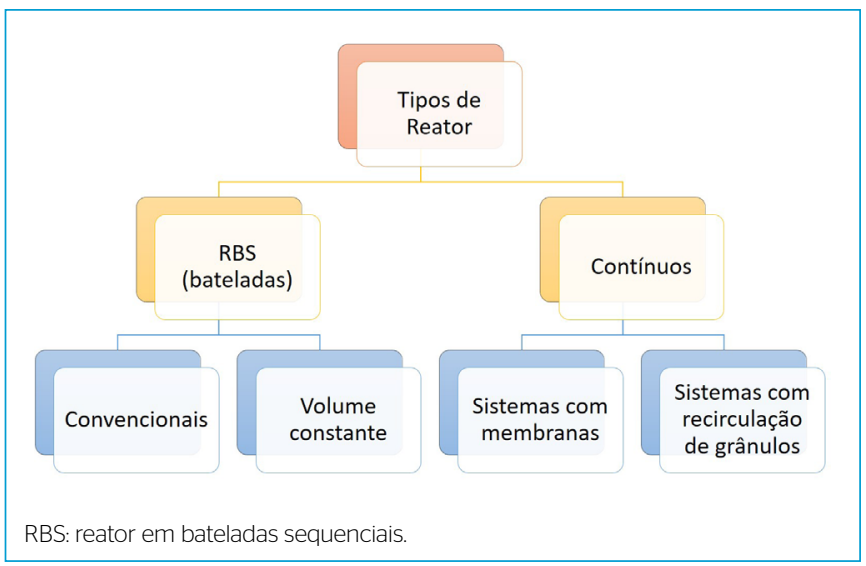

Figura 1 - Tipos de reator para o cultivo de lodo granular aeróbio (LGA). demais estão em fase de reação ou sedimentação (VAN HAANDEL; VAN DER LUBBE, 2012). Os dois arranjos possíveis estão demonstrados na Figura 2.

Com relação aos tanques de equalização (TE) utilizados a montante dos reatores de LGA (arranjo do tipo 1), muitas ETE com tecnologia de LGA costumam equipar seus TE com sensores de nível e misturadores submersíveis tipo hélice, para evitar a deposição de sólidos no fundo dos tanques. Como medida de segurança, os tanques possuem medidores de $\mathrm{pH}$ e de condutividade, a fim de alertar sobre possíveis alterações nas características do efluente a ser encaminhado para o tratamento biológico. O efluente equalizado é direcionado para os reatores biológicos por uma estação elevatória intermediária. É relevante dizer que os tanques de equalização podem ser aproveitados de antigo módulos, como sistemas de lodo ativado e outros reatores desativados, os quais devem passar por um processo de recuperação e inspeção de chapas, além da remoção das estruturas internas (BRK AMBIENTAL, 2018; ROBERTI, 2018).

\section{Sistemas contínuos}

Conforme dito, a maioria dos reatores empregados para cultivo de LGA é RBS. No entanto, diversas pesquisas utilizando sistemas contínuos foram desenvolvidas, e, até o presente momento, já existem três plantas em escala real com reatores de LGA em fluxo contínuo (KENT; BOTT; WANG, 2018). As principais configurações de sistemas contínuos adotadas são: sistemas com membrana e sistemas com recirculação. Nos reatores com membranas (membrane biological reactor - MBR), são usados tanques para formação dos grânulos e uma membrana que atua como barreira seletiva, proporcionando efluente tratado de elevada qualidade (MARTIN; CLIPPELEIR; STURM, 2016). Já nos sistemas com recirculação, observa-se a presença de um tanque de aeração, no qual ocorre a formação dos grânulos, seguido de um

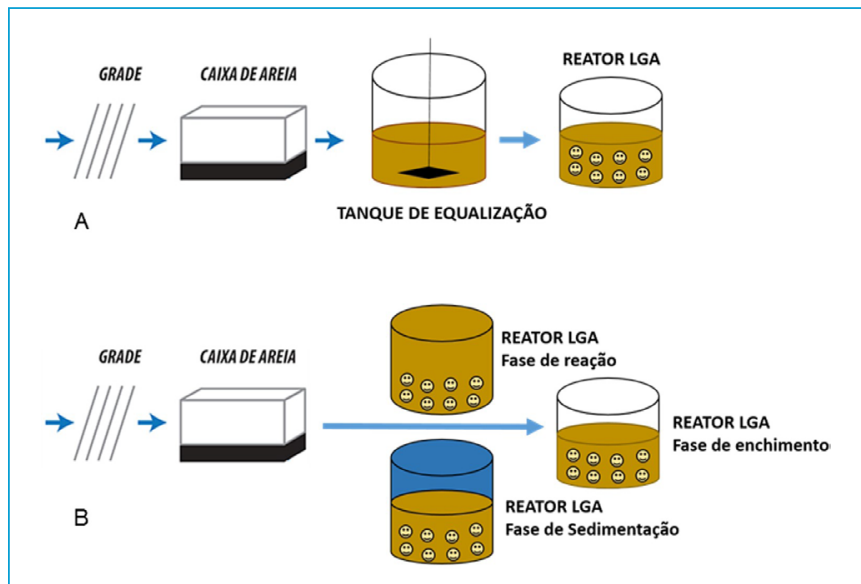

Figura 2 - Possíveis arranjos dos reatores de lodo granular aeróbio (LGA): (A) tanque de equalização seguido por reator LGA; (B) reator LGA em sistemas modulares (ausência de tanques de equalização. 
decantador, que visa à seleção do agregado granular de melhor sedimentabilidade para a recirculação para o tanque de reação (KENT; BOTT; WANG, 2018).

As vantagens dos reatores contínuos sobre os RBS são inúmeras, especialmente as relacionadas à operação. Contudo, tratando-se do cultivo de LGA, constata-se que os reatores contínuos têm levado enorme desvantagem em razão da dificuldade de se estipularem as condições essenciais para a formação dos grânulos. Nesse contexto, os maiores obstáculos do uso de reatores contínuos para LGA são: estabelecimento do período de feast (abundância de matéria orgânica) e de famine (ausência de matéria orgânica), determinação da velocidade de sedimentação mínima e problemas de se definirem fases anaeróbias seguidas de aeróbias em um mesmo tanque.

Nos experimentos realizados por Corsino et al. (2016), observou-se que grânulos semeados em MBR se desintegraram durante uma operação de 42 dias. Com relação aos sistemas de recirculação, diversos autores citaram os problemas de esmagamento/destruição dos grânulos na bomba de recirculação (LI et al., 2014).

Por mais que alguns sistemas contínuos tenham alcançado resultados satisfatórios na formação dos grânulos, viu-se que os grânulos apresentaram instabilidade e eram facilmente desintegráveis. Portanto, ainda são necessárias mais investigações em reatores de fluxo contínuo (JUANG et al., 2010).

\section{Parâmetros de projetos de reatores de lodo granular aeróbio}

Os reatores de LGA têm sido construídos principalmente em concreto, em formato cilíndrico ou retangular (NEREDA, 2018), sendo necessário um conjunto de acessórios e operações de manejo para o correto funcionamento do sistema, tais como:

- $\quad$ sistema de aeração;

- entrada ascendente do afluente;

- descarte de lodo em diferentes níveis no reator, visando à seleção dos grânulos de melhor sedimentabilidade;

- controle da idade de lodo;

- manutenção de elevadas concentrações de sólidos no reator, os quais devem possuir elevada capacidade de sedimentação;

- sistema supervisório bastante eficiente que possa promover os ajustes nos ciclos do RBS a depender dos valores de eficiências encontrados, mesmo que remotamente;

- entre outras características (VAN HAANDEL; VAN DER LUBBE, 2012).

A Tabela 1 mostra algumas configurações de reatores de LGA utilizadas na patente Nereda ${ }^{\circledR}$ do tipo RBS de volume constante. Tais informações são usadas para a concepção dos projetos e a operação das ETE, visando ao tratamento de esgoto sanitário.
Com relação ao ciclo, verifica-se que ele varia de acordo com o objetivo do tratamento, como remoção de nitrogênio, biodesfosfatação ou aproveitamento de produtos no âmbito do conceito da biorrefinaria. Na maioria das ETE de LGA que tratam esgoto sanitário, têm sido observados ciclos variáveis (geralmente com duração de 2 a 9 h). No sistema apresentado por Pronk et al. (2015), foram aplicados dois diferentes ciclos, de acordo com o regime de chuvas local. No verão, com afluente pouco diluído e maior carga orgânica, utilizou-se ciclo de 6,5 h. Por outro lado, no inverno, adotou-se ciclo de 3 h. É importante ressaltar que, além da otimização do ciclo, os reatores de LGA permitem diversas adaptações nas fases dos ciclos, como a adição de fase anóxica no fim do ciclo (após a fase aeróbia), alimentação escalonada ao longo dele, alimentação e descarte simultâneos, entre outros.

É exibida, na Tabela 2, a configuração típica empregada por alguns reatores Nereda ${ }^{\circledR}$, com ciclos de 4 h. Salienta-se que esses valores se referem a RBS de volume constante.

Tabela 1 - Configurações de reatores em bateladas sequenciais (RBS) de volume constante de lodo granular aeróbio (LGA) utilizadas na patente $\mathrm{Nereda}^{\circledR}$.

\begin{tabular}{l|c} 
Parâmetro & Valor de referência \\
\hline Velocidade média ascensional do afluente & $2-3 \mathrm{~m} / \mathrm{h}$ \\
\hline Velocidade máxima ascensional do afluente & $5 \mathrm{~m} / \mathrm{h}$ \\
\hline Velocidade mínima de sedimentação & $10 \mathrm{~m} / \mathrm{h}$ \\
\hline Volume de troca máximo & $70 \%$ \\
\hline Altura & $4-12 \mathrm{~m}$ \\
\hline Oxigênio dissolvido & $2-2,5 \mathrm{mg} \mathrm{O} / \mathrm{L}$ \\
\hline Concentração de sólidos no reator & $8-12 \mathrm{~g} \mathrm{SST} / \mathrm{L}$ \\
\hline Relação A/M & $0,2-5,0 \mathrm{~g} \mathrm{DQO} / \mathrm{g} \mathrm{SSV} \cdot$ dia \\
\hline $\mathrm{TDH}$ & $6-24 \mathrm{~h}$ \\
\hline Tempo de ciclo & $4-8 \mathrm{~h}$ \\
\hline $\mathrm{IVL} \mathrm{IO}_{30} / \mathrm{IVL}_{10}$ & $>0,9$ \\
\hline
\end{tabular}

A/M: alimento/microrganismo; TDH: tempo de detenção hidráulica; IVL: índice volumétrico de lodo; SST: sólidos suspensos totais; SSV: sólidos suspensos voláteis; DQO: demanda química de oxigênio.

Fonte: Nancharaiah e Reddy (2018) e Dezotti, Sant'Anna Jr. e Bassin (2011).

Tabela 2 - Configurações de reatores em bateladas sequenciais (RBS) de volume constante de lodo granular aeróbio (LGA) utilizadas na patente Nereda ${ }^{\circledR}$ com ciclo de $4 \mathrm{~h}$.

\begin{tabular}{l|c|c} 
Fase & Duração (min) & Fração do ciclo (\%) \\
\hline $\begin{array}{l}\text { Alimentação e descarte } \\
\text { simultâneos (condições } \\
\text { anaeróbias) }\end{array}$ & 60 & 25 \\
\hline Fase aeróbia & 165 & 69 \\
\hline Sedimentação & 15 & 6 \\
\hline
\end{tabular}


No processo de configuração do ciclo e da duração das fases, vários parâmetros devem ser analisados, sendo os principais: tipo de afluente, carga orgânica, tempo de detenção hidráulica (TDH), sólidos suspensos totais (SST), sólidos suspensos voláteis (SSV), temperatura e qualidade do efluente desejada. A principal desvantagem desse sistema está ligada às questões operacionais, pois ele necessita de elevado nível de automação dos equipamentos (VAN HAANDEL; VAN DER LUBBE, 2012).

\section{Operação de reatores de lodo granular aeróbio}

Uma das principais desvantagens da tecnologia de LGA refere-se à complexidade operacional, como a elevada automação do sistema (considerando-se a realidade do país e as condições de operação e manutenção da maioria das plantas de tratamento do Brasil). As ETE da patente $\mathrm{Nereda}^{\circledR}$, por exemplo, têm utilizado sensores on-line (oxigênio dissolvido, demanda química de oxigênio - DQO, amônia, nitrito, nitrato, fósforo total, turbidez, $\mathrm{pH}$, potencial redox, entre outros) para monitorar o desempenho do reator e para determinar a duração ótima do ciclo, além de auxiliar no descarte de lodo e em outras tomadas de decisão (NEREDA, 2018; PRONK et al., 2015).

Entre os sistemas com elevado grau de automação, cita-se a ETE Utrecht (Holanda), que trabalha com ciclos entre 4 e $8 \mathrm{~h}$, em que o período de alimentação e descarte simultâneos é constante, mas a fase de reação, variável. Nessa ETE, há vários sensores ligados a unidades de controle lógico programável (CLP). Assim, ao serem identificadas concentrações de amônia, nitrito e nitrato abaixo de $2 \mathrm{mg} / \mathrm{L}$, a aeração é interrompida, o sistema entra na fase de sedimentação e, em seguida, ocorre a alimentação/o descarte para o início de um novo ciclo (DIJK; PRONK; VAN LOOSDRECHT, 2018).

O descarte de lodo pode se dar de diversas formas. Bassin et al. (2012) propõem a remoção pelo topo e uma parcela no fundo, no entanto essa metodologia apresenta dificuldade de implantação em ETE em escala plena. Nesse sentido, Zhu et al. (2013) mostrou que o descarte de $10 \%$ do lodo de fundo resultava em aumento nas eficiências de remoção de nutrientes e na maior estabilidade do grânulo. Diferentemente dos sistemas de lodo ativado, em que o descarte se baseia apenas na idade de lodo, nos sistemas de LGA, deve-se avaliar o descarte seletivo, ou seja, o controle da idade do lodo associado à remoção do lodo de baixa sedimentabilidade. Assim, o descarte não deve ocorrer aleatoriamente no licor misto, tal como na tecnologia de lodo ativado (DEZOTTI; SANT’ANNA JR.; BASSIN, 2011; VAN HAANDEL; VAN DER LUBBE, 2012). A otimização do descarte de lodo em sistemas de LGA ainda precisa de mais investigações e tem sido considerada um desafio para sistemas em escala plena (NANCHARAIAH; REDDY, 2018).

Outro parâmetro de importância na operação de reatores de LGA é o percentual de troca volumétrica. A carga orgânica afluente ao reator LGA depende tanto da concentração de substrato afluente quanto do percentual de troca volumétrica (volume de enchimento/volume do reator). Para se manter a carga orgânica adequada (para a formação e estabilidade dos grânulos) quando o sistema for alimentado com afluente de baixa concentração, como no caso de esgoto diluído, é necessário aumentar o percentual de troca volumétrica, sendo observados valores entre 50 e 75\% (NI et al., 2009). Por outro lado, cargas muito elevadas (acima de $8 \mathrm{~kg} \mathrm{DQO} / \mathrm{m}^{3} \cdot \mathrm{d}$ ) podem causar a desintegração dos grânulos. De acordo com Tay et al. (2004), o diâmetro dos grânulos tende a crescer com o aumento da carga orgânica afluente, $\mathrm{e}$ esse aumento pode causar problemas com o tamanho e a porosidade da superfície dos grânulos (foram constatadas dificuldades na difusão de carbono para o interior dos grânulos).

\section{APLICAÇÃO DA TECNOLOGIA DE LODO GRANULAR AERÓBIO EM ESTAÇŌES DE TRATAMENTO DE ESGOTO EM ESCALA PLENA}

A biomassa granular aeróbia tem sido aplicada pela Royal HaskoningDHV Consultoria em parceria com a Universidade Tecnológica de Delft. Em 2005, essa tecnologia foi patenteada com o nome de $\mathrm{Nereda}^{\circledR}$. Sua primeira aplicação em escala real foi a melhoria de uma ETE industrial que converteu um RBS do tipo convencional em um RBS de LGA. Em seguida, outras duas plantas com a tecnologia (Gansbaai, na África do Sul, e Frielas, em Portugal) foram construídas em 2008. Em 2011, a ETE de Epe, na Holanda, foi projetada e construída para a vazão de $1.500 \mathrm{~m}^{3} / \mathrm{h}$ (PRONK et al., 2015; NEREDA, 2018). Desde a implementação dessas experiências, tem-se observado a adoção de LGA em diversos projetos de novas ETE e até mesmo em upgrade de ETE (especialmente aquelas com sistemas de lodo ativado), que passaram a utilizar a granulação aeróbia. Atualmente, há mais de 10 ETE que empregam a tecnologia (NEREDA, 2018). No Brasil, citam-se a ETE Deodoro (Rio de Janeiro), a ETE Jardim São Paulo (Recife) e a ETE Jardim Novo em Rio Claro (São Paulo), todas operadas pela BRK Ambiental.

No tocante à implantação da tecnologia de LGA no Brasil, é importante apontar o caso da ETE Deodoro (Rio de Janeiro), que foi a primeira ETE da América Latina a ter reatores de LGA em operação. A operação iniciou-se em 2016, e, na ocasião, a unidade Deodoro era a maior planta de tratamento de esgotos em operação do mundo equipada com a tecnologia de grânulos aeróbios, sendo superada em 2017 (ROBERTI, 2018). A Figura 3 mostra o fluxograma adotado na ETE Deodoro.

Ainda em relação ao reator de LGA da ETE Deodoro, ressalta-se que os reatores dessa planta possuem automação em todas as válvulas e registros, controlados por um sistema supervisório em um centro de controle operacional (CCO). O sistema também conta com instrumentos de medição e analisadores em linha, como medidores de nível, oxigênio dissolvido, temperatura, potencial redox, analisador de 
amônio, fosfato, SST, altura da manta de lodo e turbidez no ponto de saída do efluente tratado (BRK AMBIENTAL, 2018).

Os resultados apresentados pelas estações com tecnologia de LGA (Tabela 3) têm sido bastante promissores, especialmente na remoção de matéria orgânica e nutrientes, fato que se deve sobretudo ao mecanismo de nitrificação, desnitrificação e remoção de fósforo simultâneas (simultaneous nitrification, denitrification and phosphorus removal SNDPR) nos grânulos (ROLLEMBERG et al., 2018). No entanto, a questão-chave para a obtenção desses resultados está relacionada ao monitoramento em tempo real dos reatores e ao elevado grau de automação observados nesses sistemas. Dessa forma, é importante afirmar que o ótimo desempenho exibido pelo LGA não pode ser atribuído apenas aos aspectos tecnológicos, mas também aos investimentos na operação dos reatores, incluindo, muitas vezes, um sistema supervisório que opera de forma remota de fora do país. Um caso típico é a ETE Epe na Holanda, a qual foi assistida remotamente por instalações em Gansbaai e Frielas (PRONK et al., 2015). A Tabela 3 mostra os resultados das principais ETE espalhadas pelo mundo que utilizam a tecnologia de LGA no tratamento de esgoto doméstico.

Conforme se observa na Tabela 3, as ETE em escala real operadas com tecnologia de LGA têm apresentado eficiências elevadas na remoção de matéria orgânica e nutrientes. Além das vantagens já destacadas, verifica-se menor geração de lodo em comparação a sistemas aeróbios convencionais. Liu et al. (2005) constataram que a geração de lodo em sistemas de LGA chegava a ser três vezes menor que a dos sistemas de lodo ativado convencionais. Eles viram que o valor de $\mathrm{Y}$ foi inferior a $0,2 \mathrm{~g} \mathrm{SSV} / \mathrm{g} \mathrm{DBO}_{\text {removida }}$, ao passo que o valor usual de $\mathrm{Y}$ em projetos de sistemas aeróbios é $0,5 \mathrm{~g} \mathrm{SSV/g} \mathrm{DBO}$

\section{DESAFIOS PARA A IMPLANTAÇÃO DA TECNOLOGIA DE LODO GRANULAR AERÓBIO}

Embora a formação dos grânulos por meio de esgoto doméstico seja possível (XAVIER et al., 2018), a estabilidade a longo prazo

Tabela 3 - Desempenho médio das estações de tratamento de esgoto (ETE) com tecnologia de lodo granular aeróbio (LGA) no tratamento de esgoto doméstico.

\begin{tabular}{|c|c|c|c|c|}
\hline \multirow{2}{*}{ ETE } & \multirow{2}{*}{$\begin{array}{c}\text { Eficiências de } \\
\text { remoção (\%) }\end{array}$} & \multicolumn{2}{|c|}{ Referência } & \\
\hline & & NT & PT & \\
\hline Lubawa (Polônia) & $>90$ & $>90$ & $>90$ & $\begin{array}{c}\text { Swiątczak e } \\
\text { Cydzik-Kwiatkowska } \\
\text { (2018) }\end{array}$ \\
\hline $\begin{array}{l}\text { Garmerwolde } \\
\text { (Holanda) }\end{array}$ & $>90$ & $\sim 86$ & $\sim 87$ & Pronk et al. (2015) \\
\hline $\begin{array}{l}\text { Gansbaai } \\
\text { (Africa do Sul) }\end{array}$ & 94 & 90 & $>80$ & Giesen et al. (2013) \\
\hline Deodoro (Brasil) & $>90$ & $>60$ & $>50$ & Roberti (2018) \\
\hline Ryki (Polônia) & $>90$ & $>90$ & $>90$ & Nereda (2017) \\
\hline Kingaroy (Austrália) & $>90$ & 〜5 & $>90$ & Nereda (2017) \\
\hline
\end{tabular}

DQO: demanda química de oxigênio; NT: nitrogênio total; PT: fósforo total.

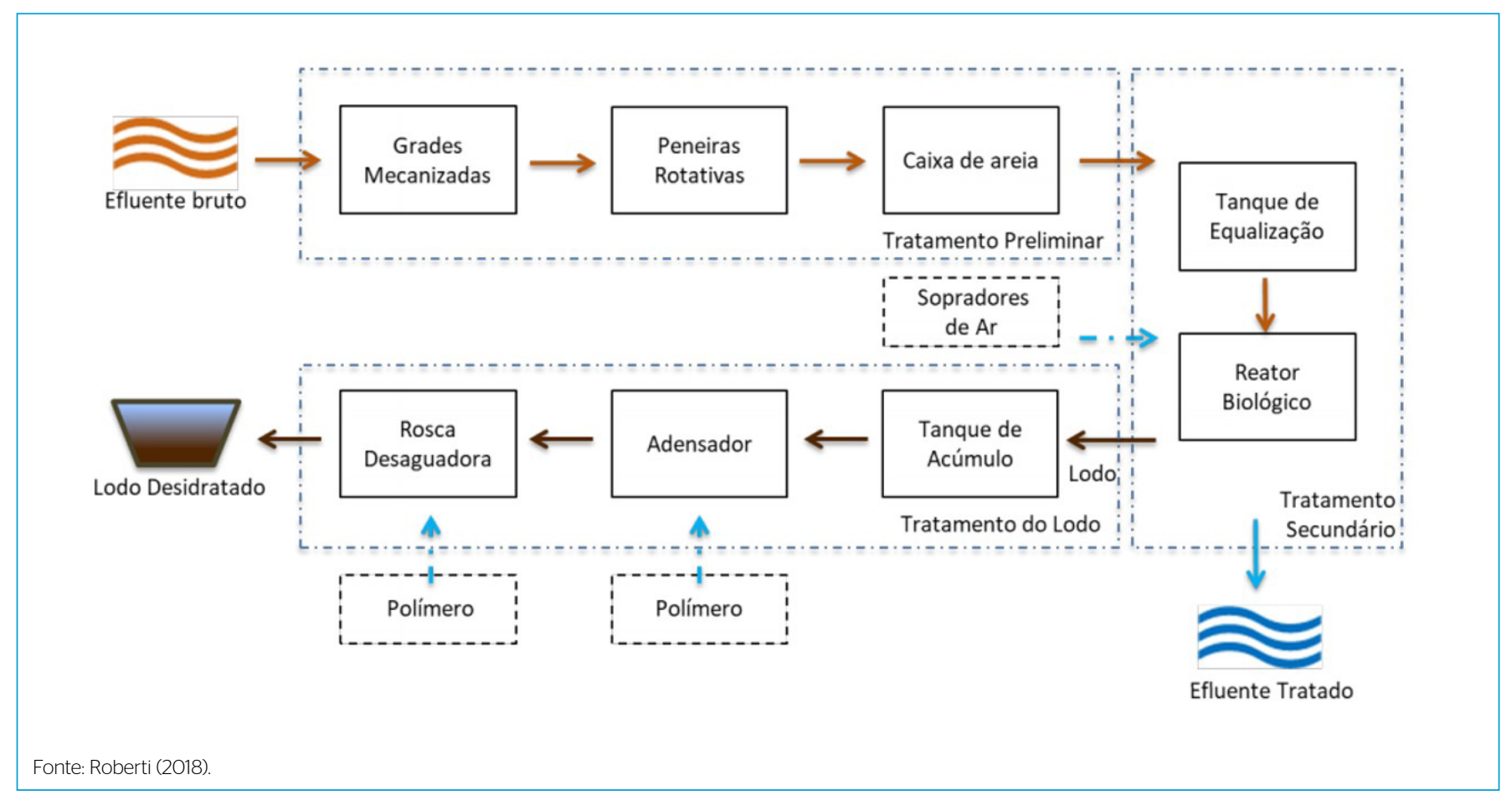

Figura 3 - Fluxograma adotado na estação de tratamento de esgoto (ETE) Deodoro. 
do LGA continua sendo uma limitação para o uso generalizado dessa tecnologia. Além disso, outros problemas podem ser citados, como: partida do sistema, complexidade operacional e elevado custo de implantação, em razão da necessidade de sondas e de sensores (FRANCA et al., 2018).

A primeira questão (partida do sistema) foi extensivamente investigada nos últimos 20 anos pela análise de vários fatores que influenciam a granulação aeróbia, o que melhorou muito o tempo de partida. Alguns autores observaram períodos superiores a um ano para que os grânulos aeróbios fossem dominantes em reatores alimentados com esgoto doméstico (LIU et al., 2010). No entanto, após o melhor entendimento do processo de granulação, verificaram-se partidas abaixo de seis meses, de cinco meses nas ETE Garmerwolde (Holanda) (PRONK et al., 2015) e Deodoro (ROBERTI, 2018), para completa granulação e estabilidade.

As principais técnicas reportadas na literatura para acelerar o processo de granulação e diminuir o tempo de partida são:

- adição externa de DQO solúvel para cultivo de grânulos aeróbios quando se pretende tratar efluentes que não favorecem o desenvolvimento de bactérias de crescimento lento (PEYONG et al., 2012);

- uso de cátions divalentes, o que pode acelerar a granulação, sendo o cálcio o composto mais estudado, pois esses cátions podem atuar na neutralização de cargas, no aumento da produção de SPE e como matriz para a formação dos grânulos (ROLLEMBERG et al., 2018);

- uso de lodo granular pré-cultivado como fonte de inóculo (PIJUAN; WERNER; YUAN, 2011).

Se, por um lado, o problema do tempo de cultivo da biomassa granular já parece estar resolvido; por outro, ainda há a preocupação com a instabilidade dos grânulos, conforme relatado na literatura (ROLLEMBERG et al., 2019; ZHANG et al., 2011). No geral, a instabilidade do LGA tem sido atribuída aos seguintes aspectos principais:

- crescimento de microrganismos filamentosos (LIU; LIU, 2006);

- hidrólise e degradação intracelular de proteínas no núcleo anaeróbio dos grânulos;

- baixo oxigênio dissolvido e consequente criação de ambientes anaeróbios com formação de metano, provocando a quebra dos grânulos;

- perda da capacidade de microrganismos de autoagregação por causa da redução de SPE;

- fenômenos de quorum sensing (QS) e quorum quenching (QQ) (FRANCA et al., 2018; ADAV; LEE; LAI, 2010).

Ainda sobre QS e QQ, ressalta-se que ambos são mecanismos de comunicação pelos quais as bactérias detectam sua densidade populacional geral, permitindo que sincronizem suas atividades. O QS está diretamente relacionado à formação e estabilização de grânulos aeróbios. Algumas características são comumente reguladas por QS, tais como: produção de SPE, produção de enzimas específicas e formação de biofilme. Por outro lado, o QQ é o mecanismo de inibição das atividades bacterianas e, portanto, está associado à desagregação dos grânulos (BZDRENGA et al., 2017).

Vários estudos propuseram soluções para a instabilidade apresentada nos sistemas de LGA, entre as quais:

- controlar o tamanho dos grânulos entre 1 e $3 \mathrm{~mm}$ por meio da taxa de aeração e descarte de lodo (TOH et al., 2003);

- controlar a idade de lodo ótima (próxima a 10 dias) para favorecer os microrganismos de crescimento lento (ZHU et al., 2013);

- selecionar microrganismos que auxiliam na estabilidade dos grânulos sob condições específicas de alimentação, como aumento da relação N/DQO, que favorece o cresscimento de bactérias nitrificantes (LIU; YANG; TAY, 2004), ou pela garantia de condições de feast, na fase anaeróbia, e famine, em praticamente todo o período aeróbio, visando à seleção de PAO e GAO (FRANCA et al., 2018);

- ajustar a taxa de aeração ao longo do período famine para reduzir o consumo de SPE (LIU; TAY, 2006).

Embora muitos métodos tenham sido propostos, observa-se que a sua aplicação em escala plena se apresenta, muitas vezes, inviável. Além disso, ressalta-se que, geralmente, as ETE que tratam esgoto doméstico não alcançam valores de eficiência tão elevados quanto os obtidos nos experimentos de laboratório. Na ETE Deodoro, por exemplo, após 272 dias de operação, viu-se que apenas 5,6\% dos grânulos possuíam diâmetro superior a $0,2 \mathrm{~mm}$ e menos de $1 \%$ possuía diâmetro superior a $1 \mathrm{~mm}$. Também se verificou o acúmulo de nitrato ao longo do período de operação (o que mostra que o mecanismo de nitrificação e desnitrificação simultâneas provavelmente não ocorreu, principalmente em função do baixo diâmetro dos grânulos), apontando também para a baixa remoção de fósforo nessa ETE (em média de 50 a 60\%), enquanto, em muitos estudos, são reportadas remoções acima de 90\% (HE et al., 2018).

\section{CONCLUSÃO}

A tecnologia de LGA é, de fato, uma das mais promissoras tecnologias emergentes de tratamento de esgotos, não somente no tocante à remoção de poluentes, como também pela menor demanda de área e de energia da ETE. No entanto, apesar dos avanços alcançados ao longo dos últimos anos, com possibilidade até mesmo de recuperação de recursos, como alginato, triptofano e PHA, alguns aspectos ainda precisam ser melhorados, como o problema da estabilidade 
do LGA (fator-chave para a operação em longo prazo). Finalmente, faz-se necessária uma avaliação criteriosa quanto à capacidade de pagamento de muitos municípios do Brasil, em que a referida tecnologia vem substituindo sistemas de baixo custo de tratamento de esgotos, como reatores anaeróbios de manta de lodo e fluxo ascendente (upflow anaerobic sludge blanket - UASB), seguidos de pós-tratamento.

\section{AGRADECIMENTOS}

Os autores agradecem o apoio recebido do Conselho Nacional de Desenvolvimento Científico e Tecnológico (CNPq), da Coordenação de Aperfeiçoamento de Pessoal de Nível Superior (CAPES), da Fundação de Amparo à Pesquisa do Estado de Minas Gerais (FAPEMIG) e do Instituto Nacional de Ciência e Tecnologia em Estações Sustentáveis de Tratamento de Esgoto (INCT ETEs Sustentáveis).

\section{REFERÊNCIAS}

ADAV, S.S.; LEE, D.J.; LAI, J.Y. (2010) Microbial community of acetate utilizing denitrifiers in aerobic granules. Applied Microbiology and Biotechnology, v. 85, n. 3, p. 753-762. https://doi.org/10.1007/s00253009-2263-6

BASSIN, J.P.; KLEEREBEZEM, R.; DEZOTTI, M.; VAN LOOSDRECHT, M.C.M. (2012) Simultaneous nitrogen and phosphate removal in aerobic granular sludge reactors operated at different temperatures. Water Research, v. 46, n. 12, p. 3805-3816. https://doi. org/10.1016/j.watres.2012.04.015

BRK AMBIENTAL. (2018) Tecnologia Nereda - Tratamento de esgotos sanitários com biomassa granular aeróbia. In: ENCONTRO NACIONAL DAS AGUAS, 7., 2018, São Paulo. Anais...

BZDRENGA, J.; DAUDÉ, D.; RÉMY, B.; JACQUET, P.; PLENER, L.; ELIAS, M.; CHABRIËRE, E. (2017) Biotechnological applications of quorum quenching enzymes. Chemico-Biological Interactions, v. 267, p. 104-115. https://doi.org/10.1016/j.cbi.2016.05.028

CORSINO, S.F.; CAMPO, R.; BELLA, G.; TORREGROSSA, M.; VIVIANI, G. (2O16) Study of aerobic granular sludge stability in a continuousflow membrane bioreactor. Bioresource Technology, v. 200, p. 1055-1059. https://doi.org/10.1016/j.biortech.2015.10.065

DE KREUK, M.K.; HEIJNEN, J.J.; VAN LOOSDRECHT, M.C.M. (2005) Simultaneous COD, nitrogen, and phosphate removal by aerobic granular sludge. Biotechnology and Bioengineering, v. 90, n. 6 , p. 761-769. https://doi.org/10.1002/bit.20470

DE KREUK, M.K.; VAN LOOSDRECHT, M.C.M. (2006) Formation of aerobic granules with domestic sewage. Journal of Environmental Engineering, Rio de Janeiro, v. 132, n. 6, p. 694-697. https://doi. org/10.1061/(ASCE)0733-9372(2006)132:6(694)

DEZOTTI, M.; SANT'ANNA JR., G.L.; BASSIN, J.P.; (2011) Processos biológicos avançados para tratamento de efluente e técnicas de biologia molecular para o estudo da diversidade microbiana, Rio de Janeiro: Interciência.

DIJK, E.J.H.V.; PRONK, M.; VAN LOOSDRECHT, M.C.M. (2018) Controlling effluent suspended solids in the aerobic granular sludge process. Water Research, v. 147, p. 50-59. https://doi. org/10.1016/j.watres.2018.09.052
FRANCA, R.D.G.; PINHEIRO, H.M.; VAN LOOSDRECHT, M.C.M. LOURENÇO, N.D. (2018) Stability of aerobic granules during longterm bioreactor operation. Biotechnology Advances, v. 36, n. 1 , p. 228-246. https://doi.org/10.1016/j.biotechadv.2017.11.005

GIESEN, A.; DE BRUIN, L.M.M.; NIERMANS, P.P.; VAN DER ROEST, H.F. (2013) Advancements in the application of aerobic granular biomass technology for sustainable treatment of wastewater. Water Practice \& Technology, v. 8, n. 1, p. 47-54. https://doi.org/10.2166/wpt.2013.007

HE, Q.; SONG, Q.; ZHANG, S.; ZHANG, W.; WANG, H. (2018) Simultaneous nitrification, denitrification and phosphorus removal in aerobic granular sequencing batch reactor with mixed carbon sources: reactor performance, extracellular polymeric substances and microbial successions. Chemical Engineering Journal, v. 331, p. 841-849. https://doi.org/10.1016/j.cej.2017.09.060

HOU, C.; SHEN, J.Y; ZHANG, D.J.; HAN, Y.; MA, D.H.; SUN, X.Y.; LI, J.S.; HAN, W.Q.; WANG, L.J.; LIU, X.D. (2017) Bioaugmentation of a continuous-flow self-forming dynamic membrane bioreactor for the treatment of wastewater containing high-strength pyridine. Environmental Science Pollution Research, v. 24, n. 4, p. 3437-3447. https://doi.org/10.1007/s11356-016-8121-z

ISAKA, K.; DATE, Y.; SUMINO, T.; YOSHIE, S.; TSUNEDA, S. (2006) Growth characteristic of anaerobic ammonium-oxidizing bacteria in an anaerobic biological filtrated reactor. Applied Microbiology Biotechnology, v. 70, n. 1, p. 47-52. https://doi.org/10.1007/s00253005-0046-2

JUANG, Y.C.; ADAV, S.S.; LEE, D.J.; TAY, J.H. (2010) Stable aerobic granules for continuous-flow reactors: precipitating calcium and iron salts in granular interiors. Bioresource Technology, v. 101, n. 21, p. 8051-8057. https://doi.org/10.1016/j.biortech.2010.05.078

KENT, T.R.; BOTT, C.B.; WANG, Z. (2018) State of the art of aerobic granulation in continuous flow bioreactors. Biotechnology Advances, v. 36, n. 4, p. 1139-1166. https://doi.org/10.1016/j. biotechadv.2018.03.015

LEE, D.J.; CHEN, Y.Y.; SHOW, K.-Y.; WHITELEY, C.G.; TAY, J.-H. (2O10) Advances in aerobic granule formation and granule stability in the course of storage and reactor operation. Biotechnology Advances, v. 28, n. 6, p. 919-934. https://doi.org/10.1016/j.biotechadv.2010.08.007 
LI, J.; CAI, A.; WANG, M.; DING, L.B.; NI, Y.J. (2014) Aerobic granulation in a modified oxidation ditch with an adjustable volume intraclarifier. Bioresource Technology, v. 157, p. 351-354. https://doi.org/10.1016/j. biortech.2014.01.130

LIU, X.W.; YU, H.Q; NI, B.J.; SHENG, G.P. (2009) Characterization, modeling and application of aerobic granular sludge for wastewater treatment. In: ZHONG, J.J.; BAI, F.W.; ZHANG, W. (orgs.). Biotechnology in China I. Advances in Biochemical Engineering/ Biotechnology. Berlim: Springer. v. 113. p. 275-303. https://doi. org/10.1007/10_2008_29

LIU, Y.; LIU, Q.S. (2006) Causes and control of filamentous growth in aerobic granular sludge sequencing batch reactors. Biotechnology Advances, v. 24, n. 1, p. 115-127. https://doi.org/10.1016/j. biotechadv.2005.08.001

LIU, Y.; WANG, Z.-W.; QIN, L.; LIU, Y.-Q.; TAY, J.H. (2005) Selection pressure-driven aerobic granulation in a sequencing batch reactor. Applied Microbiology and Biotechnology, v. 67, n. 1, p. 26-32. https:// doi.org/10.1007/s00253-004-1820-2

LIU, Y.; YANG, S.F.; TAY, J.H. (2004) Improved stability of aerobic granules through selecting slow-growing nitrifying bactéria. Biotechnology, v. 108, n. 2, p. 161-169. https://doi.org/10.1016/j. jbiotec.2003.11.008

LIU, Y.L.; KANG, X.R.; LI, X; YUAN, Y.X. (2015) Performance of aerobic granular sludge in a sequencing batch bioreactor for slaughterhouse wastewater treatment. Bioresource Technology, v. 190, p. 487-491. https://doi.org/10.1016/j.biortech.2015.03.008

LIU, Y.Q; MOY, B.; KONG, Y.H.; TAY, J.H. (2010) Formation, physical characteristics and microbial community structure of aerobic granules in a pilot-scale sequencing batch reactor for real wastewater treatment. Enzyme and Microbial Technology, v. 46, n. 6, p. 520-525. https://doi.org/10.1016/j.enzmictec.2010.02.001

LIU, Y.Q; TAY, J.H. (2006) Variable aeration in sequencing batch reactor with aerobic granular sludge. Journal of Biotechnology, v. 124, n. 2, p. 338-346. https://doi.org/10.1016/j.jbiotec.2005.12.037

MARTIN, K.A.S.; CLIPPELEIR, H.; STURM, B. (2016) "Accidental granular sludge?": Understanding process design and operational conditions that lead to low SVI-3O values through a survey of full scale facilities in North America. In: WEFTEC, 2016. Anais... Nova Orleans: Water Environment Federation. p. 3396-3405. https:/l dx.doi.org/10.2175/193864716819713367

MORGENROTH, E.; SHERDEN, T; VAN LOOSDRECHT, M.C.M.; HEIJNEN, J.J; WILDERER, P.A. (1997) Aerobic granular sludge in a sequencing batch reactor. Water Research, v. 31, n. 12, p. 3191-3194. https://doi.org/10.1016/S0043-1354(97)00216-9

NANCHARAIAH, Y.V:; REDDY, G.K.K. (2018) Aerobic granular sludge technology: Mechanisms of granulation and biotechnological applications. Bioresource Technology, v. 247, p. 1128-1143. https://doi. org/10.1016/..biortech.2017.09.131

NEREDA. (2017) Aerobic Granular Sludge Demonstration. Holanda: BACWA.
NEREDA. (2018) Nereda ${ }^{\oplus}$ Technology - Wastewater Treatment Solutions by Royal Haskoning DHV. Holanda.

NI, B-J.; XIE, W.-M.; LIU, S-G.; YU, H.-Q; WANG, Y.Z.; WANG, G.; DAI, X.-L. (2009) Granulation of activated sludge in a pilot-scale sequencing batch reactor for the treatment of low-strength municipal wastewater. Water Research, v. 43, n. 3, p. 751-761. https://doi.org/10.1016/j.watres.2008.11.009

PEYONG, Y.N.; ZHOU, Y.; ABDULLAH, A.Z:; VADIVELU, V. (2O12) The effect of organic loading rates and nitrogenous compounds on the aerobic granules developed using low strength wastewater Biochemical Engineering Journal, v. 67, p. 52-59. https://doi. org/10.1016/j.bej.2012.05.009

PIJUAN, M.; WERNER, U.; YUAN, Z. (2O11) Reducing the startup time of aerobic granular sludge reactors through seeding floccular sludge with crushed aerobic granules. Water Research, v. 45, n. 16, p. 5075-5083. https://doi.org/10.1016/..watres.2011.07.009

PRONK,M:DEKREUK,M.K:DEBRUIN,B;:KAMMINGA,P; KLEEREBEZEM, R.; VAN LOOSDRECHT, M.C.M. (2015) Full scale performance of the aerobic granular sludge process for sewage treatment. Water Research, v. 84, p. 207-217. https://doi.org/10.1016/j.watres.2015.07.011

QIN, L., LIU, Y. (2008) Aerobic granulation at different settling times. In: LIU, Y. (org.). Wastewater purification: aerobic granulation in sequencing batch reactors. Boca Raton: CRC Press. p. 51-67.

ROBERTI, G. (2018) Start-up of a full-scale aerobic granular sludge system: evaluation of biomass formation and its performance in the biological treatment of sanitary sewage. 106f. Dissertação (Mestrado em Engenharia Ambiental) - Faculdade de Engenharia, Universidade do Estado do Rio de Janeiro, Rio de Janeiro.

ROLLEMBERG, S.L.S.; BARROS, A.R.M.; FIRMINO, PIIM.; DOSSANTOS, A.B. (2018) Aerobic granular sludge: cultivation parameters and removal mechanisms. Bioresource Technology, v. 270, p. 678-688. https://doi.org/10.1016/j.biortech.2018.08.130

ROLLEMBERG, S.L.S.; OLIVEIRA, L.Q.; BARROS, A.R.M.; MELO, V.M.M.; FIRMINO, P.I.M.; DOS SANTOS, A.B. (2019) Effects of carbon source on the formation, stability, bioactivity and biodiversity of the aerobic granule sludge. Bioresource Technology, v. 278, p. 195-204 https://doi.org/10.1016/j.biortech.2019.01.071

SANTOS, E.V.M. (2014) Estratégias para predominância de organismos acumuladores de fósforo em sistemas de lodo ativado e respirometria aplicada à biodesfosfatação. 268f. Tese (Programa de Pós-Graduação em Ciência e Tecnologia Ambiental) - Universidade Estadual da Paraíba, Campina Grande.

ŚWIATTCZAK, P.; CYDZIK-KWIATKOWSKA, A. (2018) Performance and microbial characteristics of biomass in a full-scale aerobic granular sludge wastewater treatment plant. Environmental Science and Pollution Research International, v. 25, p. 1655-1669. https://doi.org/10.1007/s11356-017-0615-9

TAY, J.H.; PAN, S.; HE, Y.; TAY, S.T.L. (2004) Effect of Organic Loading Rate on Aerobic Granulation. I: Reactor Performance. Journal of Environmental Engineering, v. 130, n. 10, p. 1094-1101. https://doi. org/10.1061/(ASCE)0733-9372(2004)130:10(1094) 
TOH, S.K.; TAY, J.H.; MOY, B.Y.P.; IVANOV, V.; TAY, S.T.L. (2003) Sizeeffect on the physical characteristics of the aerobic granule in a SBR. Applied Microbiology and Biotechnology, v. 60, p. 687-695. https://doi.org/10.1007/s00253-002-1145-y

VAN HAANDEL, A.C.; VAN DER LUBBE, J. (2012) Handbook biological wastewater treatment: design and optimization of activate sludge systems. Londres: IWA Publishing.

WAGNER, J.; GUIMARÃES, L.B.; AKABOCI, T.R.V.; COSTA, R.H.R. (2O15) Aerobic granular sludge technology and nitrogen removal for domestic wastewater treatment. Water Science and Technology, v. 71, n. 7, p. 1040-1046. https://doi.org/10.2166/wst.2015.064

WANG, F.; LU, S.; WEI, Y.; JI, M. (2009) Characteristics of aerobic granule and nitrogen and phosphorus removal in a SBR. Journal of Hazardous Materials, v. 164, n. 2-3, p. 1223-1227. https://doi. org/10.1016/j.jhazmat.2008.09.034

XAVIER, J.A.; GUIMARÃES, L.B.; LEITE, W.R.; MARTINS, C.L.; DAUDT, G.C.; COSTA, R.H.R. (2018) Granulação natural em reator operado em bateladas sequenciais: características dos grânulos e desempenho no tratamento de esgoto sanitário. Engenharia
Sanitária Ambiental, v. 23, n. 6, p. 1067-1077. https://doi.org/10.1590/ s1413-41522018174914

ZHANG, B.; JI, M.; QIU, Z.; LIU, H.; WANG, J.; LI, J. (2011) Microbial population dynamics during sludge granulation in an anaerobicaerobic biological phosphorus removal system. Bioresource Technology, v. 102, n. 3, p. 2474-2480. https://doi.org/10.1016/j. biortech.2010.11.017

ZHANG, Q.; HU, J.; LEE, D.J. (2016) Aerobic granular processes: Current research trends. Bioresource Technology, v. 210, p. 74-80. https://doi.org/10.1016/j.biortech.2016.01.098

ZHOU, D.; NIU, S.; XIONG, Y.; YANG, Y:; DONG, S. (2014) Microbial selection pressure is not a prerequisite for granulation: Dynamic granulation and microbial community study in a complete mixing bioreactor. Bioresource Technology, v. 161, p. 102-108. https://doi. org/10.1016/j.biortech.2014.03.001

ZHU, L.; YU, Y.; DAI, X.; XU, X.; QI, H. (2013) Optimization of selective sludge discharge mode for enhancing the stability of aerobic granular sludge process. Chemical Engineering Journal, v. 217, p. 442-446. https://doi.org/10.1016/j.cej.2012.11.132 